\title{
HISTÓRIA E HISTÓRIA DA EDUCAÇÃO NO PROJETO DE FORMAÇÃO DE PROFESSORES NA DÉCADA DE 30 NO BRASIL: PROBLEMATIZANDO AS NOÇÕES de Afrânio Peixoto
}

\author{
Carlos Eduardo Vieira** \\ Roberlayne de Oliveira Borges Roballo***
}

\section{RESUMO}

Em termos científicos amplos é objetivo deste trabalho investigar as concepções, em sentido amplo, de História e de história da educação presentes nas obras que serviram de suporte para os processos de formação de professores, a partir da década de 30 no Brasil. Considerando a dimensão deste problema neste trabalho, optamos por recortar a análise em torno da primeira obra produzida e editada para este fim específico no país, intitulada Noções de história da educação, de Afrânio Peixoto. Publicada em 1933 pela Companhia Editora Nacional - no âmbito do projeto editorial dirigido por Fernando de Azevedo e intitulado "Biblioteca pedagógica brasileira" -, a obra encerra sentidos importantes para compreendermos o lugar da história e da história da educação no projeto de formação de professores associado ao Movimento pela Escola Nova (MEN). As Noções foram publicadas com o objetivo manifesto de aperfeiçoar cultural e profissionalmente os futuros professores. Sendo assim, escolhemos como fontes para essa investigação as primeiras edições da obra. A perspectiva metodológica que informa esse empreendimento visa compreender as relações entre a obra e seu contexto de produção. Em outros termos, pensamos a obra na sua relação intra e extratextual, ou seja: por um lado, a entendemos como expressão de idéias sobre o conhecimento histórico que tinham uma finalidade formativa associada à escola normal e, por outro, como evidência de um contexto intelectual no qual ela estava em sintonia. A escrita da história da educação, pensada para

\footnotetext{
* Artigo recebido em 29/3/2007 e aprovado em 28/8/2007.

** Pesquisador do CNPQ. Professor do Programa de Pós-Graduação em Educação da Universidade Federal do Paraná. E-mail: cevieira@ufpr.br

** Mestre em Educação. E-mail: roberlayneroballo@hotmail.com
} 
os processos de formação de professores, assumiu características próprias e a sua especificidade, segundo concluímos, estava relacionada com as representações produzidas sobre os destinatários das Noções (normalistas), bem como em função do papel conferido à história nos processos de formação.

Palavras-chave: Formação de professores; Escola Normal; História.

\section{INTRODUÇÃO}

Este trabalho se insere em uma investigação sobre as concepções, em sentido amplo, de História e de história da educação presentes nas obras que serviram de suporte para os processos de formação de professores, a partir da década de 30 no Brasil. Considerando a dimensão deste problema, neste momento, optamos por recortar a análise em torno da primeira obra produzida e editada para este fim específico no país, intitulada Noções de história da educação, de Afrânio Peixoto. Publicada em 1933 - pela Companhia Editora Nacional, no âmbito do projeto editorial dirigido por Fernando de Azevedo, intitulado "Biblioteca pedagógica brasileira" -, a obra encerra sentidos importantes para compreendermos o lugar da História e da história da educação no projeto de formação de professores associado ao Movimento pela Escola Nova (MEN). ${ }^{1}$

Afrânio Peixoto, autor privilegiado neste estudo, nasceu em Lençóis, na Bahia, em 17 de dezembro de 1876, e faleceu na cidade do Rio de Janeiro, em 12 de janeiro de 1947. Formou-se na Faculdade de Medicina, em 1897, em Salvador. Em 1901, foi nomeado professor substituto de Medicina Pública na Faculdade de Direito da Bahia. No mesmo ano, mudou-se para o Rio de Janeiro e, em 1902, tornou-se Inspetor Sanitário de Saúde Pública do Distrito Federal. Em 1904, assumiu a direção interina do Hospício Nacional de Alienados. Retornando ao Brasil, após uma longa viagem por muitos países da Europa, foi classificado em primeiro lugar, mediante concurso, como professor das cadeiras de Higiene e Medicina Legal da Faculdade de Medicina do Rio de Janeiro. Foi empossado também na cátedra de Medicina Pública da Faculdade de Ciências Jurídicas do Rio de Janeiro.

A carreira de sucesso na área médica não contentou este intelectual que, tal como muitos dos expoentes da elite letrada da época, notabilizouse por uma intervenção social ampla e multifacetada. Na década de 1910, 
percebemos claramente a manifestação desta tendência de intensa e diversificada ação social, de tal maneira que a especialidade do médico, a erudição do literato, o magistério do educador e a vocação política do intelectual encontraram-se na trajetória e na produção científico-literária de Peixoto. Neste período, ele foi eleito membro da Academia Brasileira de Letras, ocupando o lugar de Euclides da Cunha, chegando em 1923 à presidência da academia. ${ }^{2}$ No plano político, foi deputado federal pela Bahia em 1924 e reeleito na legislatura seguinte. Na sua atuação no Parlamento, chamou a atenção para temáticas como malária, acidentes de trabalho, analfabetismo e insânia mental. No plano da educação, Peixoto foi diretor da Escola Normal do Rio de Janeiro e diretor geral da Instrução Pública do Distrito Federal, nos anos 1915 e 1916, respectivamente. Lecionou História da Educação nos cursos de formação de normalista. Em 1932, foi signatário do célebre Manifesto dos Pioneiros da Educação Nova, junto com Fernando de Azevedo, Anísio Teixeira e outros tão célebres. Nos anos seguintes, tornar-se-ia o primeiro reitor da Universidade do Distrito Federal (UDF).

O cidadão do mundo Peixoto foi um viajante contumaz. Conheceu a Europa e as suas instituições acadêmicas, científicas e educacionais. Foi também ao Oriente buscar inspiração para sua literatura e, na América do Norte, encontrou o modelo de organização política e cultural com qual se identificou: a democracia liberal.

Magistério, medicina legal e higiene, política, literatura e poesia, administração pública foram as principais áreas de intervenção deste intelectual. A formação de Peixoto, como evidenciam os dados de sua biografia, sintetizou o encontro entre os seguintes projetos formativos: a especialidade médica, apoiada na ciência positiva, e as humanidades, com base nas letras, na história e na filosofia. A autoridade do médico, somada à aura de erudição do sábio, legitimou a palavra e as ações deste intelectual na ágora moderna. Com seu discurso socialmente autorizado, Peixoto afirmava que todos os males do Brasil resumiam-se em um único fator determinante: "privação, deficiência, ou perversão da educação física, intelectual, cívica ou política" (Регхото, 1950, p. 170). ${ }^{3}$ A condição vital dos homens e a condição vital da democracia, segundo ele, se realizariam caso fosse assegurado o direito e o dever da instrução popular. Nesses termos, Peixoto reiterava o refrão da intelectualidade do período que elegeu a educação como projeto social prioritário. Negligenciar tal 
projeto, segundo as representações da época, significaria não alcançar a desejada modernidade.

Peixoto, para além das suas singularidades irredutíveis, expressa de maneira exemplar três características importantes da elite letrada do período que, nesta investigação, conceitualizamos como intelectuais modernos. Em síntese, concebemos o conceito com base em três aspectos que induzimos da análise das trajetórias e das idéias de inúmeros agentes da vida intelectual brasileira no período: 1) sentimento de pertencimento a estrato social específico (intelectuais), com base na construção de uma identidade que - independente de credo, origem social e ideologia - se estrutura na competência, familiaridade e/ou formação para lidar com a cultura, seja ela artística, filosófica, científica ou pedagógica; 2) empenho e engajamento político, a partir de um sentimento de missão social; 3) por fim, defesa da centralidade da questão educativa/formativa no projeto moderno de reforma social. ${ }^{4}$

LiÇÕES DE CIVISMO, ENTUSIASMO PELO LIVRO E O LUGAR DO BRASIL NA CIVILIZAÇ̃̃O OCIDENTAL

O sentimento de missão social movia a intelectualidade a ocupar múltiplos púlpitos, entre os quais destacamos: a imprensa; a escola (universidades, escolas normais etc.); o Estado, segundo os cargos públicos ocupados; e, de maneira intensa na experiência de Peixoto, a produção de livros. Em 1939, durante uma viagem a Nova Iorque, Armando Vidal pediu que Afrânio escrevesse um artigo sobre o livro brasileiro para ser distribuído na forma de folhetos, na Feira Mundial que se realizaria naquela cidade. Afrânio assim o fez afirmando que, mais do que linhas escritas, o livro é uma representação significativa do que o homem necessita. Os livros representam, segundo Peixoto, potentes instrumentos para ensinar um povo a pensar. A crença no poder do livro revela-se a crença na força das idéias, uma vez que, para Peixoto,

se um objeto pode dar indício de uma civilização será este o Livro. É uma arte ou uma técnica, complexiva. Diz tudo. Por fora e por dentro [...] Foi o livro, sem dúvida, que mudou a Idade Média em Renascimento. O mundo moderno data da imprensa, que fez o livro. Fez também os jornais, os livros cotidianos e efêmeros; também a América está preparando o mundo de amanhã, com o disco, com o 
cinema, que não se precisam ler, que se ouvem, livros que não dão trabalho, que até divertem, livros até dos que não sabem ler. (Регхото, 1950, p. 246-247)

Ainda segundo Peixoto:

Se o livro é índice de cultura, o nosso país pode já ser acreditado. Se todos não lêem, quase todos os brasileiros escrevem. E acabarão por lerem, todos os que escrevem. Ao menos as próprias obras. O livro tem, pois, um futuro certo e promissor, no Brasil. Livro é progresso. (Регхото, 1950, p. 248)

O livro foi a grande paixão de Peixoto e, neste sentido, asseverava: "outrora, era a fé que respondia a tudo; depois foi a Universidade; agora é o livro [...] A verdadeira Universidade é o livro" (p. 175). Peixoto escreveu aproximadamente cento e quarenta obras; em média, seus livros tinham de três a oito edições. Sua intensa produção científica e literária ocorreu entre 1910 e 1940, sendo considerado um dos autores com maior número de leitores. Estreou na literatura com a publicação, em 1900, do livro Rosa mística, um drama cercado da atmosfera do simbolismo. Estudioso do vernáculo, particularmente da obra camoniana, interessavase pelos antigos autores portugueses. A sua bibliografia é vasta e nela tanto aparece o romancista, o crítico, o cientista, o historiador e o educador. Na obra A esfinge (1911), escrita após sua viagem ao Egito, mostrou o conflito entre homem e mulher, transpostos para o Rio de Janeiro, num ambiente requintado e repleto de diálogos sobre política, mundanismo, negócios e assuntos literários. Entre os seus romances, que constituem uma galeria de tipos femininos, citam-se: A esfinge (1911), Maria Bonita (1914), Fruta do mato (1920), Razões do coração (1925), Bugrinha (1922), Sinhazinha (1929), Uma mulher como as outras (1928). O tema da mulher predominou na sua literatura e revelou-se também de forma intensa no seu magistério, no seu intento de dar lições às normalistas.

Entre as obras sobre a temática da saúde e da medicina, destacamos: Medicina legal (1911), Noções de higiene (1918), Elementos de higiene (1912). Escreveu também sobre temas políticos e históricos: Minha terra e minha gente (1915), José Bonifácio, o velho e o moço (1920). A crítica, a filologia e a história da literatura brasileira também mereceram obras: Trovas brasileiras (1919), Parábolas (1920), Castro 
Alves - o poeta e o poema (1922), Camões e o Brasil (1927), História da literatura brasileira (1931), Panorama da literatura brasileira (1940), e, em colaboração com Pedro Pinto, Dicionário dos Lusíadas (1924).

$\mathrm{Na}$ condição de um dos homens mais representativos da cultura brasileira do período, Peixoto dirigia seu pensamento e guiava sua ativa pena em diferentes direções. Durante décadas, apaixonou-se sucessivamente por temas variados, por países como a França, Portugal e os Estados Unidos, como também por personalidades da vida cultural, tais como Castro Alves e Camões. O ethos nacionalista, presente de maneira intensa na atmosfera intelectual do período, revelava-se intimamente articulado ao projeto de formação do povo, tendo em vista as idéias de formação e de difusão da consciência nacional. Aos intelectuais apoiados nos seus poderes de compreensão, de síntese e de expressão caberia a elaboração desta consciência e à escola caberia a missão de disseminá-la. Segundo Peixoto:

A mesma raça se desune em povos diversos, a mesma religião não reúne povos diferentes: Gregos, Romanos, Germanos, Iberos foram assim. Serão assim os BRASILEIROS. Uma nação, define Renan, é uma grande solidariedade, constituída pelo conhecimento dos sacrifícios feitos, dos sacrifícios ainda por fazer; resume-se, no presente, em fato concreto: o desejo, o consentimento inequívoco de continuar a vida comum [...] O que nos cumpre é preparar, hoje, o Brasil de amanhã. Educar o brasileiro de agora para lhe dar uma consciência de si e, portanto, dar a todos uma consciência nacional. (1950, p.78)

Através da educação, segundo Peixoto, poderemos ter democracia, pois, "para exercer o seu direito, o homem precisa conhecer-se e aos seus deveres". Os povos ignorantes abdicam de si e passam a servir aos outros. Um Brasil próspero, segundo ele, deveria ser instruído e educado, honrando a cultura greco-latina, as tradições lusitanas e a sua própria história. Conclui Peixoto: "Só há um caminho para a conquista da natureza, dos homens, de si mesmo: saber. Não há outro meio de o conseguir: querer". Percebemos nestas passagens a evidente preocupação cívicopatriótica, a crença no poder da educação, bem como a intenção de mobilizar o povo e a nação para alcançar os fins propalados.

A compreensão da singularidade de Peixoto não nos impede de perceber os traços que o uniam à elite letrada do seu tempo: discurso 
nacionalista, crença na educação, desejo de modernidade e convicção sobre o papel dos intelectuais na formação do povo e na construção da nação. Verificamos também o papel conferido ao ensino da história nesse processo de formação. O estudo da história universal e pátria estava associado à idéia de nos reconhecermos como nação, com identidade própria, bem como percebermos como esta identidade é parte de um processo que nos une aos gregos, aos latinos e, mais recentemente, aos portugueses. Cultuar as heranças gregas, latinas e lusitanas e, sobretudo, as tradições nacionais permitiria ao povo brasileiro se reconhecer como herdeiro e como protagonista do desenvolvimento da civilização ocidental.

HisTÓRIA DA EDUCAÇ̃̃O NO PROCESSO DE FORMAÇÃO DAS PROFESSORAS: APENAS NOÇÕES

$\mathrm{Na}$ frente editorial, o projeto formativo do magistério do grupo vinculado ao MEN teve em Fernando de Azevedo o seu principal protagonista. O empreendimento editorial intitulado "Biblioteca pedagógica brasileira", da Companhia Editora Nacional, foi o grande marco desta estratégia. De 1931 a 1960, na série "Atualidades pedagógicas" foram publicados 77 títulos, além de reedições, dos quais pelo menos oito, segundo Miriam Jorge Warde (1998), podem ser classificadas como obras de história da educação. A primeira a ser publicada sobre esta temática foi a obra Noções de história da educação. Nos termos do próprio Peixoto, no prefácio da segunda edição de 1936, o primeiro e único livro voltado para a formação do magistério que trabalha com a temática da história da educação (Регхото, 1942, p. 8).

Segundo Diana Gonçalves Vidal (2001), no ano de 1937, o livro de Peixoto estava na categoria dos livros mais referenciados nos programas de ensino do Instituto de Educação do Distrito Federal. Em 1933, foi publicada a primeira edição de Noções, com uma tiragem de aproximadamente mil exemplares; trata-se de um número bastante expressivo para a época. Em 1936, teríamos a segunda edição e, em 1942, a terceira. Na primeira edição, o livro tem 20 capítulos e 282 páginas, sendo reservados três capítulos para a história da educação brasileira (RochA, 2001, p. 22). Na terceira edição, o livro passa a ter 21 capítulos e 357 páginas, sendo perceptível que os capítulos sobre a educação no Brasil tiveram um acréscimo significativo de páginas. 
Nas Noções, a história da educação é tratada como evolução das idéias pedagógicas, revelando uma concepção da escrita da história da educação apoiada nas crenças do poder das idéias e da centralidade na cultura dos ícones da história intelectual da filosofia e da pedagogia. A periodização assume a clássica divisão das histórias da civilização de extração iluminista. No prefácio da segunda edição, Peixoto comenta que foi acusado por alguns exigentes de discutir as idéias educativas em sintonia com a história da civilização. Peixoto responde a seus críticos dizendo que a "história da civilização é a história dos resultados da educação" (Регхото, 1942, p. 8). A idéia de unir história da civilização e história da educação foi uma opção clara para Peixoto, pois, na sua concepção, o grau de civilização alcançado pela humanidade estava intimamente associado ao grau de empenho educativo assumido pelos povos e pelas culturas.

A obra foi dividida em três partes: educação antiga, educação medieval e educação contemporânea. Estranhamente, a educação moderna é um capítulo da parte que trata da educação medieval. A primeira parte versa sobre a educação dos selvagens e primitivos, dos povos orientais e culmina com a análise dos filósofos gregos e dos retóricos romanos. A cultura grega e o Império Romano, seguindo a clássica tradição historiográfica, inauguram a chamada civilização ocidental. Peixoto, nesta primeira parte, expressou sua crítica sobre certas formas de educação, considerando-as arcaicas, tais como a chinesa e a indiana. Sobre Grécia e Roma, o tom de enaltecimento não impede que ele critique a exclusão da mulher dos processos educacionais, bem como a escravidão e os castigos corporais. Aproxima este período do século vinte, quando utiliza determinados conceitos que objetivam, nos seus próprios termos, atravessar o tempo: "Havia escolas, poder-se-ia dizer, de primeiro, segundo e terceiro graus, ou como dizemos hoje, primárias, secundárias e superiores, bem que os antigos não as distinguissem precisamente" (Регхото, 1942, p. 70).

$\mathrm{Na}$ segunda parte, o foco é a educação medieval, com ênfase para os padres educadores, a escolástica, o surgimento das universidades e o Renascimento, entendido como o canto do cisne daquele período, e, sobretudo, a educação na idade moderna. Peixoto preocupou-se em mostrar o papel da mulher, assim como em criticar a escolástica por causa de suas discussões rigorosas, porém inúteis. Na seqüência, considera a reforma protestante e a contra-reforma movimentos 
reacionários e, sem pudores, afirma que Rousseau era meio louco; porém, acredita que foi por intermédio dele que Pestalozzi, Froebel e a escola progressiva surgiram.

Na terceira parte, que se trata da educação contemporânea, a lógica de expor noções de filosofia e de pedagogia a partir da trajetória e das idéias dos ícones do pensamento se acentua. Sendo assim, idéias sobre Pestalozzi, Herbart, Froebel, Comte, Stuart-Mill são expostas a partir de fontes que os leitores e os críticos não têm acesso. Esse procedimento de eclipsar as fontes na narrativa produz um completo apagamento da relação empiria-reflexão. Não há sequer, no final da obra, um elenco de obras de referência utilizadas pelo autor. A afirmação, exposta no prefácio da primeira edição, de que "era preferível uma perspectiva panorâmica, a campos microscópicos e meramente documentais" (Регхото, 1933, p. 7), foi realmente levada às últimas conseqüências, uma vez que os vestígios sobre a documentação mobilizada para a construção da narrativa foram cuidadosamente omitidos.

É uma história da educação sem fontes declaradas e que busca estabelecer suas conexões com a cultura, a economia, a política, enfim, com outros contextos societários, a partir de um procedimento sui generis de iniciar os capítulos por um item denominado sincronismo. Neste são arrolados, em ordem cronológica, acontecimentos que, provavelmente, foram considerados pelo autor como significativos na história e que se encontram cronologicamente aproximados dos problemas e das idéias educacionais tratadas no capítulo. As relações entre estes acontecimentos e os contextos educacionais abordados ficam apenas sugeridas, pois não há, por parte do autor, esforço analítico visando demonstrar estas conexões. Cabe ainda ressaltar a presença recorrente nos diferentes itens que tratam sobre o sincronismo de episódios da história política e militar, tais como invasões, sucessões e batalhas; da história intelectual, tais como a criação de bibliotecas, universidades e o aparecimento de obras; bem como episódios que compõem a história religiosa, em particular, o cristianismo.

Na última parte - depois de deslocados itens sobre surdos-mudos, cegos, deficientes mentais e menores abandonados -, surgem dois capítulos específicos sobre os Estados Unidos, um sobre a América Latina e três sobre o Brasil. O Brasil e os Estados Unidos são os únicos países a receberem destaque especial. A ênfase nesta parte da obra está em dar conselhos às futuras professoras. 
Nos capítulos sobre o Brasil, vislumbramos teses sobre a história da educação no país que serão, posteriormente, reafirmadas por Fernando de Azevedo, na Cultura brasileira (1943). Em síntese, a narrativa discorre sobre os jesuítas e as suas iniciativas de educar os índios e os colonos e de organizar a primeira rede de escolas na Colônia. Os juízos sobre o papel histórico desempenhado pelos padres da Companhia de Jesus são francamente favoráveis, pois, segundo Peixoto, eles trouxeram eqüidade entre brancos e negros e civilizaram os índios que viviam na promiscuidade e na poligamia. Críticas duras a Pombal são delineadas pela expulsão dos jesuítas e, sobremaneira, pela dissolução da pequena estrutura educacional existente. No mesmo tom ácido, Peixoto execra o Ato Adicional (1834) por ter descentralizado as ações educativas no Império. Em suma, as iniciativas do Estado colonial e imperial, em termos de educação, foram trágicas. A República demora a organizar o campo educacional, mas a partir dos anos 20 e 30 a idéia de um sistema público de ensino organizado em nível nacional ganha força e dá esperanças aos educadores brasileiros. $\mathrm{Na}$ frente desse projeto redentor, os pioneiros da educação nova que, após mais de cento e cinqüenta anos de falta de iniciativas consistentes, retomam a iniciativa no campo educacional brasileiro.

Sobre a América Latina, afirma:

Passando a vista na cronologia latina da América dois fenômenos, um físico, outro social, chamam logo a atenção: são os terremotos e as revoluções. Parecem-se, bem que independam. Sismos da terra e do homem, explicados pela natureza vulcânica de toda a cordilheira de montanhas que beira o Pacífico e pela natureza rude, ineducada, de toda a descendência latina na América. O contraste com a América inglesa é frisante: pela educação está ela learderando o mundo; a América latina é pasto do caudilhismo militar e civil, que não sabe governar-se, e, mando e usufruto dos bens públicos, destrói a ordem interna ou pêlea com os vizinhos do continente, continuamente...

Agora mesmo estão quase todos em revoluções internas e quatro em estado de guerra. (Регхото, 1942, p. 269)

Fica claro sua aversão ao tema da revolução, tal como pudemos perceber na sua análise sobre a política na América Latina. Em momento anterior do texto, ele associa o mal educado, o mal asseado e o revolucionário. Nos termos do próprio Peixoto: “o mal educado começou 
no desasseiado, no 'mal-ouvido ', no 'mal criado' e chega a desordeiro, rebelde, criminoso, revoltado, revolucionário" (Регхото, 1942, p. 235).

A educação americana, nos dois capítulos dedicados a este país, assume na narrativa de Noções a condição de modelo de educação moderna: a América não teve deuses, nem reis, foi sempre uma heterogênea democracia (Регхото, 1942, p. 251). Por fim, no último capítulo, o movimento pela escola nova é analisado. Peixoto considera o projeto da escola nova o único capaz de construir uma sociedade civilizada, moderna e portadora de condições iguais de educação para todas as classes sociais. Peixoto, associado ao discurso renovador, reitera a base científica da escola nova, sua capacidade para educar em um mundo em mudança e, em especial, a estreita relação entre escola nova, sociedade industrial e democracia. Nesta direção, assevera Peixoto:

Convém os entendidos que a escola nova só foi, é, ou será possível pelos progressos das ciências biológicas, que deram ao homem uma compreensão do universo e da natureza, sem ilusões, ou prejuízos; pela filosofia científica que explica a vida não mais apenas pelos fenômenos físico-químicos, mas por uma dinâmica funcional, donde uma fisiologia, uma psicologia e portanto uma ética, a ela condicionados; pela civilização que se transforma, changing civilization, com o maquinismo industrial, com a economia do trabalho, com o advento da democracia, técnica e real. (1942, p. 331)

As três partes e os inúmeros capítulos dos selvagens à escola nova revelam uma concepção linear, cronológica e evolutiva das idéias educativas na história. A obra visa representar a saga da civilização na sua evolução rumo à modernidade que, nos termos postos em Noções, materializa-se na democracia liberal, na indústria e na escola nova. A obra encerra uma concepção de história escatológica, articulada a uma gênese (cultura greco-romana), a um processo de desenvolvimento (Idade Média, Renascimento, Iluminismo etc.) e um fim (sociedade moderna). Em termos de idéias educacionais, a presença do tema da escola nova no último capítulo da obra visa representar esta concepção da pedagogia como o último elo deste longo processo civilizatório, marcado pela luta entre o arcaico e o moderno, entre o selvagem e o civilizado.

As teses da escola nova concluem a obra, porém estiveram presentes na problematização das Noções ao longo de todo o itinerário de evolução histórica das idéias pedagógicas, pois elas exercem na 
narrativa peixotiana a função de contraponto para a realização dos julgamentos sobre os acertos ou sobre os erros dos antigos, dos medievais e/ou dos modernos. Esta transferência dos valores do presente para julgar o passado, bem como o permanente esforço de apontar erros e acertos na história, revelam duas marcas fortes dessa espécie de escrita da história: o anacronismo e a exemplaridade. Tanto o primeiro como o segundo procedimentos são partes de uma operação intelectual que busca na história utilidade, ou melhor, elementos de justificação e de legitimação de projetos educativos e políticos em curso no presente. Peixoto mobiliza noções do passado no interior de uma estratégia discursiva interessada em intervir no presente e conquistar o futuro.

Na posição de intelectual legitimado pela posse da ciência e das humanidades, de professor da Universidade do Rio de Janeiro (título inscrito abaixo do seu nome na capa da terceira edição de Noções), Peixoto fala às professoras sobre a história, corrigindo os mortos pelos seus erros ou enaltecendo-os pelos seus acertos quando estes se aproximam de sua visão de sociedade moderna e de educação nova. Neste sentido, o médico Peixoto representou a sociedade como um organismo, de tal maneira que pôde ao longo das Noções diagnosticar as doenças e prescrever os remédios. Defendeu também uma concepção de educação como processo de adaptação do indivíduo à sociedade (socioplástica) e, na mesma chave de leitura organicista, sustentou que tal processo envolve a adaptação para a vida: cívica, através da formação da consciência nacional; profissional, a partir da formação do técnico útil à sociedade industrial; e intelectual, através do domínio do método científico da observação e da experimentação.

Longe do ideal de neutralidade e de objetividade propalado pelos seus pares no IHGB, Peixoto revela constante e explícito posicionamento em sua narrativa, oferecendo às professoras noções sobre o passado e, sobretudo, lições sobre a conduta a ser adotada no presente. A recusa de um estilo ascético e analítico em favor de um tom apaixonado e doutrinário era parte de uma estratégia para produzir o convencimento e a adesão das normalistas ao projeto do MEN.

\section{À GUISA DE CONCLUSÕES}

A história da educação, entendida como disciplina de formação do magistério, teve sua origem no século XIX na Europa, enquanto no 
Brasil ela foi inserida no currículo da escola normal no fim dos anos vinte do século passado, a partir das iniciativas de intelectuais sintonizados com o projeto do MEN. No horizonte desste grupo, a história da educação não ocupou um lugar entre as chamadas ciências fontes da educação, tal como a Psicologia, a Sociologia e a Biologia. A disciplina, juntamente com a Filosofia da Educação, não foi considerada como fonte científica matricial da pedagogia moderna, contudo tinha certamente suas funções no projeto de formação do magistério. As chamadas ciências fontes, na expressão repetida insistentemente por Anísio Teixeira, representavam o esforço de conferir cientificidade à formação do magistério, rompendo com a improvisação e a tradição irrefletida e buscando, em mundo que entronizava a ciência, legitimidade social ao estudo e à prática pedagógica. A história da educação, embora não ocupasse um lugar de destaque na hierarquia dos saberes pedagógicos, cumpriu basicamente três funções: formação moral e cívica dos professores; formação pedagógica, através do reconhecimento dos acertos e dos erros do passado; e, por fim, produção da memória do grupo de intelectuais que liderava o projeto de renovação do pensamento e das práticas educacionais. A obra Noções, escrita por um professor de história da educação, mostra-se estreitamente sintonizada com as funções conferidas para a disciplina de História da Educação pelo projeto formativo de professores elaborado pelo grupo vinculado ao MEN.

A obra revela também as representações do autor sobre o público a que se destinava o texto e sobre a profissão docente. E, neste sentido, o aspecto mais evidente destas representações está, talvez, na palavra Noções presente no título. Noções do passado que, como bem afirma o autor no prefácio da primeira edição, têm como finalidade precípua a formação pedagógica e não a discussão meramente histórica e documental. A finalidade da obra era a formação de professores, logo noções de história seriam suficientes para ensejar o propósito principal, ou seja, refletir sobre os fins da educação com base em uma panorâmica e anacrônica relação com o passado. A ausência de remissão às fontes, a presença de sínteses abrangentes e o estilo doutrinário permitiriam à obra, nos próprios termos de Peixoto, evitar uma leitura fatigante e, assim, cumprir a sua missão educativa. Em outros termos, o livro, instrumento de intervenção social privilegiado por Peixoto, conquistaria os corações, formaria a consciência e mobilizaria as professoras para a realização 
dos fins considerados legítimos, oportunos e necessários para a conquista da modernidade educacional e da civilidade social.

Nos termos de Edgar Morin (1986): quando os filósofos descem de sua torre de marfim ou os técnicos ultrapassam sua área de aplicação especializada para defender, ilustrar ou promulgar teses que têm valor cívico, social ou político, eles se tornam intelectuais. ${ }^{5}$ A partir desta acepção, podemos concluir que Peixoto foi um intelectual, pois a análise que realizamos de sua trajetória e da sua obra evidencia o intenso engajamento do médico, do professor, do literato e do gestor público na cena política brasileira. Peixoto, nos termos postos pelo conceito de intelectual moderno que enunciamos no início desta reflexão, assumiu a condição de partícipe de um grupo social específico (intelectuais); revelou sentimento de missão social e engajou-se politicamente; e, por fim, defendeu a centralidade da questão educativa/formativa no projeto moderno de reforma social.

Ao longo deste trabalho, buscamos evidenciar também a concepção de história e de história da educação presente na obra Noções, entendida como parte de uma estratégia de luta pelo projeto cultural e político do grupo dos renovadores. Sinteticamente, visamos demonstrar que nas Noções encontramos um procedimento intelectual apoiado nos sentidos da pragmática, da exemplaridade, da escatologia e do anacronismo na produção da escrita da história da educação. A escrita de Peixoto é pragmática porque visa, antes de compreender o passado, dizer o que é preciso fazer no presente. ${ }^{6}$ É exemplar porque trata o estudo do passado como lição, como momento de compreensão dos erros e dos acertos cometidos pelas gerações anteriores. Trata-se de uma escrita escatológica, uma vez que adere à filosofia da história do progresso, apoiada na inexorabilidade da evolução e da modernização da sociedade, bem como assume a idéia de fim na história. O anacronismo desta narrativa é decorrente da perspectiva de problematizar o passado, da história antiga à história moderna, a partir dos problemas políticos e educacionais em disputa nos anos 30 do século passado.

A importância maior de análise desta obra não está na produção da crítica metodológica à escrita da história de Peixoto, pois seus procedimentos historiográficos eram, no seu próprio período, frágeis para o olhar de um especialista. Contudo, apesar desta inconsistência, seu texto produziu grande impacto sobre os processos de formação do magistério, assim como suas teses principais sobre a história da educação 
no Brasil. Podemos ainda afirmar que os seus procedimentos historiográficos anacrônicos, escatológicos, pragmáticos e exemplares reverberaram na produção da escrita da história da educação no Brasil por um período histórico significativo. A questão que se impõe não é a qualidade historiográfica de Noções, mas sim, em sentido lato, a sua capacidade de produção da memória educacional e, em sentido stricto, sua presença na elaboração da escrita da história da educação.

\section{ABSTRACT}

The objective of this study is to research in a broad sense the conceptions of History and the History of Education in the works used as a support for the process of teacher formation in Brazil, from the 1930s onwards. On considering the dimensions of this problem, in this paper we opt to cut off the analysis around the first work produced and edited in the country, for this specific purpose, Afrânio Peixoto's Noções de História da Educação. Published in 1933 by the Companhia Editora Nacional - as part of the editorial project directed by Fernando de Azevedo and entitled Biblioteca Pedagógica Brasileira - the work includes important orientation for understanding the place of History and the History of Education in the project for teacher formation, associated with the Movement for the New School. The Noções were published with the distinct objective of forming future teachers, both culturally and professionally. So the first editions of this work were chosen as sources for this investigation. The methodological approach used seeks to understand the relationship between the work and its historical context. In other words, the work is seen in its intra and extra-textual relations, that is: on the one hand, we understand it as an expression of ideas on historical knowledge which had a formative purpose associated to the 'Normal School', and on the other, as evidence of an intellectual context with which it was in harmony. The writing of the History of Education, envisaged for the processes of teacher formation, assumed its own characteristics and peculiarity, as we conclude, was related to the representations produced on the receivers of the Noções (students at 'Normal School'), as well as the function of the role conferred on History in the formation processes.

Key words: Formation of teachers. Normal School. History.

\section{NOTAS}

1. Acreditamos que seja necessário evitarmos uma visão do MEN de maneira demasiadamente maniqueísta (católicos contra liberais), episódica (pioneiros) e/ou homogeneizadora (escolanovista). Nesse sentido, utilizaremos, ao longo 
do texto, a expressão Movimento pela Escola Nova para nos referirmos, em sentido amplo, ao movimento cultural que, a partir da década de 20 no Brasil, mobilizou um conjunto significativo de intelectuais brasileiros em torno de um projeto que, nas palavras de Lourenço Filho, visava à organização nacional através da organização da cultura. A designação Movimento pela Escola Nova não nos parece livre de ambigüidades, porém acreditamos que seja menos restritiva, uma vez que enfatiza o processo, o movimento, as alianças, as rupturas, as assimilações e as desassimilações ocorridas no seu interior.

2. Na academia, pertenceu à comissão de Redação da Revista (1911-1920); à comissão de Bibliografia (1918) e à Comissão de Lexicografia (1920 e 1922). Em 1923, por sua iniciativa, a academia iniciou uma série de suas publicações, sob o título de "Biblioteca de Cultura Nacional", numa coleção que, em 1931, passa a ter o nome de "Coleção Afrânio Peixoto", em homenagem a seus feitos.

3. As citações de Peixoto utilizadas neste trabalho, com a data de 1950, foram extraídas do livro Afrânio Peixoto, organizado pelo ex-aluno e admirador L. Ribeiro. Trata-se de uma antologia de textos e de pensamentos de Peixoto sobre diferentes temas.

4. O conceito de intelectual moderno, com base em três sentidos (identidade, engajamento e centralidade do projeto de formação), vem sendo elaborado e desenvolvido na pesquisa, apoiada pelo CNPq, Processo n. 306010/2004-6, intitulada Intelectuais, Educação e modernidade: Da escola moderna ao movimento pela Escola Nova (1900-1950), sob a responsabilidade de Carlos Eduardo Vieira.

5. Sobre a posição de Edgar Morin em torno da temática dos intelectuais ver, deste autor, Para sair do século $X X$.

6. Utilizamos a noção de escrita pragmática da história da educação a partir da referência do texto Questões teóricas e de método: a história da educação nos marcos de uma disciplina, de Mirian Jorge Warde.

\section{REFERÊNCIAS}

BASTOS, E. R; RÊGO, W. D. L. Intelectuais e política: a moralidade do compromisso. São Paulo: Olho D’Água, 1999.

BOMENY, H. et al. Constelação Capanema: intelectuais e políticas. Rio de Janeiro: FGV, 2001.

CARVALHO, M. M. A história da educação no Brasil. In: CARVALHO, M. M. (Org.). A escola e a república e outros ensaios. Bragança Paulista: EDUSF, 2003. p. 281-312. 
FARIA FILHO, L. M.; VIDAL, D. História da educação no Brasil: a constituição histórica do campo (1880-1970). Revista Brasileira de História, São Paulo, v. 23, n. 45, 2003. p. 37-70.

GONDRA, J. G. (Org.). Pesquisa em história da educação no Brasil. Rio de Janeiro: DP\&A, 2005.

LOPES, E M T; GALVÃO, A. M. O. História da educação. Rio de Janeiro: DP\&A, 2001.

LOPES, M. A. Pena e espada: sobre o nascimento dos intelectuais. In: LOPES, M. A. (Org.). Grandes nomes da história intelectual. São Paulo: Contexto, 2003.

MICELI, S. Intelectuais à brasileira. São Paulo: Companhia das Letras, 2001.

PEIXOTO, A. Noções de história da educação. São Paulo: Companhia Editora Nacional, 1942.

ROCHA, H. P. Recordação para professoras: a história da educação brasileira narrada por Afrânio Peixoto. In: GONDRA, J. Dos arquivos à escrita da história: educação brasileira entre o Império e a República no século XIX. Bragança Paulista: EUSF, 2001.

RIBEIRO, L. Afrânio Peixoto. Rio de Janeiro: Conde, 1950.

VIDAL, D. G. O exercício disciplinado do olhar: livros, leituras e práticas de formação docente no Instituto de Educação do Distrito Federal (1932-1937). Bragança Paulista: Universidade de São Francisco, 2001.

VIEIRA, C. E. Anísio Teixeira e a pesquisa em educação no Brasil: ensaio sobre o processo de formação do campo. Série Estudos Periódico do Mestrado Em Educação da Ucdb, Campo Grande, v. 1, n. 15, 2003. p. 167-178.

WARDE, M. J. Lorenzo Luzuriaga entre nós. In: SOUZA, C. P.; CATANI, D. (Org.). Práticas educativas, culturas escolares e profissão docente. São Paulo: Escrituras, 1998.

WARDE, M. J. Questões teóricas e de método: a história da educação nos marcos de uma disciplina. In: SAVIANI, D.; LOMBARDI, J. C.; SANFELICE, J. L. (Org.). História e historiografia da educação: o debate teórico-metodológico atual. Campinas: Autores Associados, 1998. 